\title{
Convergencias y divergencias. (Lecturas heterodoxas de la filosofía griega), Ángela Sierra González
}

Sandra Hernández Reyes

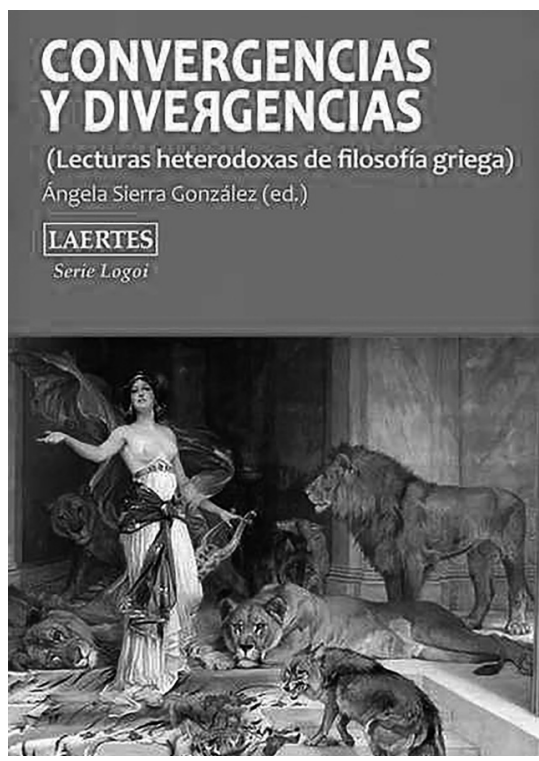

Gónzález, Ángela Sierra. Convergencias y divergencias (Lecturas heterodoxas de la filosofía griega). España: Laertes, 2018.
Lo que ha hecho clásicos a los textos de la Grecia antigua ha sido su inagotable potencia, la cual cruza el tiempo y el espacio. Sin embargo, la mediación no siempre es percibida, no se considera común que esta continua presencia de los clásicos se debe a lecturas que permiten su re-presentación en problemáticas contemporáneas. Por tanto, debe ponerse bien en claro esta mediación para comprender el modo en que impacta nuestra cultura y, sobre todo, la producción y reflexión académica. Sin detenernos en ejemplos que se encuentran a la mano en todos los idiomas dominantes de la filosofía, es posible advertir lo recurrente que son los estudios que pretenden un rescate del pensar de los 
clásicos; en éstos también es notorio que en su intención ya está el malestar contemporáneo por la recuperación: mirar hacia otro lado con expectativas de novedad. La diferencia entre quienes aspiran a recuperar el pasado en su pureza y quienes pretenden volver a él desde el presente de modo crítico es, sin duda, la conciencia de mediación; los primeros niegan la mediación y se asumen como exploradores que retratan de modo puro el saber rescatado, mientras que los estilos críticos asumen su posición actual, conscientes de su impureza y problemáticas, se saben buscadores de respuestas o quizá de preguntas.

En 2018 fue publicado en la editorial española Laertes el libro Convergencias y divergencias (Lecturas heterodoxas de filosofía griega), editado por la doctora Ángela Sierra González, un libro que ofrece un ejercicio de mediación crítica, un claro ejemplo de lo que llamamos conciencia de mediación o de impureza, según la perspectiva adoptada. Desde la in- troducción escrita por la editora, nos encontramos con ese situarse en los "síntomas que definen una crisis general de lo conocido que desdibuja la filosofía griega antigua en un espacio de conflictos teóricos viejos y nuevos". Ésta es la circunstancia que, explica Sierra, "obliga revisitar a los clásicos. A buscar respuestas en ellos mediante la confrontación crítica”. Si atendemos este planteamiento como una suerte de hilo de Ariadna que nos guía por la lectura, podríamos decir que los capítulos están entrelazados por esa preocupación, la cual se esfuerzan en hacer evidente o, mejor aún, no pretenden negarla a cada párrafo. Todos los capítulos se sitúan en el borde o "el fin de una propuesta civilizatoria", que promovió lo que conocemos como mundo Occidental. Así, la conciencia de mediación obliga a saberse dentro de un diálogo que siempre es interpretativo y no está a salvo de peligros, sin ignorarlos, asume que "toda mirada se hace desde un ángulo, desde un enfoque". ${ }^{1}$

Ángela Sierra González, editora, Convergencias y divergencias (Lecturas heterodoxas de la filosofía griega) (Еspańa: Laertes, 2018), 13. 
Los capítulos que componen el libro son tipos singulares, no comparten la misma extensión ni se caracterizan por estudiar un periodo histórico, tampoco se concentran en un texto común sobre el cual variar lecturas, y tampoco se colocan desde un interés temático común. El hilo conductor —aquel de Ariadna que guía la lectura- es que son lecturas heterodoxas realizadas por cada autor desde sus propias fuentes.

De este modo, resulta muy interesante notar cómo el capítulo de Víctor Hugo Méndez Aguirre nos lleva por la construcción de un mito dado en el cruce entre magia, política y religión. Este mito, el de la autoctonía de los atenienses, es precisamente resultado de un diálogo y cruces interpretativos que dan lugar a un "suelo natal". ${ }^{2}$ Restaría que nosotros, lectores interesados en el mundo actual, tomáramos en cuenta los acontecimientos que ocurren no sólo en España sino también en diversas partes del mundo, funda- dos en la identidad nacional donde se cruzan mitologías, religiones y la política globalizada.

Siguiendo el orden de aparición de los capítulos, nos encontramos con una temática que Michel Foucault colocó en el centro de una amplia reflexión académica. Ariane Aviñó McChesney nos lleva a conocer los pliegues de una ontología del sí mismo en su capítulo titulado "Ariadna habita los pliegues. Foucault y la ontología de sí mismo”. Es destacable, sin duda, el modo en que señala la "problemática identificación de la figura mítica” en cuestión, al revisar las representaciones que de ella se han hecho, una identidad — paradójicamente no sustancial - inferida del contexto donde aparece. "Ariadna no es ese sujeto ajeno a la voluntad, al dolor, al tiempo", esto se pone en marcha desde una lectura deleuziana de Foucault que puede, a manera de ensamblaje, arrojar una crítica continuada a las identidades puras que hoy se promueven des-

Víctor Hugo Méndez Aguirre, "Título", en Sierra González, Convergencias y divergencias, 34.

Ariane Avińó McChesney, "Ariadna habita los pliegues. Foucault y la ontología de sí mismo”, en Sierra González, Convergencias y divergencias, 54. 
de las políticas neoliberales y apelan a la ciudadanía fundada en una metafísica de la tierra, como la analizada por Méndez en el capítulo anterior.

Amanda Núnez García nos ofrece una lectura singular del cosmopolitismo: sostiene que en el cinismo y el estoicismo antiguo se obtienen algunas directrices para pensar lo cosmopolita, sobre todo "rescatar el gesto griego en filosofía política [en] el contexto actual". ${ }^{4}$ Así pues, Núñez sostiene que dicho gesto es la atmósfera del "humor y la provocación" encontrada "más cercana a los y las humoristas", pues por su velocidad de impacto "habría que estimar las viñetas de los periódicos y cómics para hacer política más que los titulares de los mass media". 5

En el siguiente capítulo, "Grecia como ideal en el marco de la globalización", prosigue la preocupación por la globalización y, quizá también, por la identidad, toda vez que pretende "aprovechar algunas enseñanzas de los griegos para corregir algunas derivas preocupantes de la civilización occidental en el marco de la actual globalización". ${ }^{6}$ El esfuerzo de Francisco J. Martínez está en marcar distancia del mundo presente para "pensar de nuevo", lejos de la autoconciencia y el cristianismo. Desde ahí recupera la fisis de un modo distinto, alejándose del sentido de utilidad que le ha dado nuestra cultura, así encuentra que una opción podría ser la autoconstitución estética, que devendría en la estilización de la existencia. Según Martínez, esto revitalizaría la democracia; destaca tanto la responsabilidad como el coraje para vigilar los asuntos públicos. Finalmente, asume que esta propuesta, extraída desde su lectura de Grecia, es un germen y no un modelo.

Aida Míguez Barciela elabora "Krisis como proceso cognitivo en la Odisea”; orienta su investigación por "cómo es posible estar críticamente en eso en lo que siempre ya estamos, la cuestión de una 'crisis' con carácter fenomenológico-cognoscitivo". 7 Para

\footnotetext{
Amanda Núnez García, "Título”, en Sierra González, Convergencias y divergencias, 90.

Núñez García, “Título”, 105.

Francisco J. Martínez, "Grecia como ideal en el marco de la globalización”, en Sierra González, Convergencias y divergencias, 111.

Aida Míguez Barciela, "Krisis como proceso cognitivo en la Odisea”, en Sierra González, Convergencias y divergencias, 137.
} 
esta indagación, hace una comparación entre el retorno de Odiseo y los prisioneros de la caverna platónica; ubica la dinámica común entre lo que provoca la crisis y aquello que ésta produce, encuentra un lugar común en el desarraigo que permite apreciar "aquello que de ordinario no vemos sencillamente porque estamos demasiado cerca, demasiado inmersos", algo que sin duda emerge como un proceso cognitivo. ${ }^{8}$

El capítulo seis corre a cargo de la editora, quien analiza cuidadosamente la relación entre "Violencia y justicia. La relevancia política del derecho del más fuerte"; se enfoca en la discusión que tiene lugar en el diálogo "Gorgias" de Platón, particularmente entre Calicles y Trasímaco. La autora destaca dos visiones del gobierno impuesto por el más fuerte, así muestra cómo la visión de la política y la justicia es la del más poderosos y el más fuerte, quienes no tienen necesidad de discutir ni pactar; para Trasímaco lo justo es lo útil para el más fuerte. Tanto la ley como el sometimiento u obediencia a ella están determinados por su utilidad y conveniencia para los más fuertes, esto se contrapone con la visión socrática de la democracia, percibida por los dos anteriores como una visión propia de esclavos. Estas discusiones, señala Ángela Sierra, apuntan no sólo a la ley sino a la fuente de ésta, ya sean los más fuertes o la mayoría; argumenta la autora que cada modelo promueve un tipo de héroe y que la propuesta de cambios en las ideas de justica y ley apunta también a "una nueva clase de heroísmo, además de un nuevo concepto de legitimidad jurídica y política". ' Sostiene que "Toda cultura política crea un modelo de individuo heroico y el ciudadano colaborativo era el modelo de la sociedad democrática. Se trataba de un heroísmo fundado en la cooperación”. Quizá sea una de las afirmaciones más interesantes de este capítulo, pues apunta sin duda a los textos anteriores que indagan en

Míguez Barciela, "Krisis como proceso", 151.

Ángela Sierra González, "Violencia y justicia. La relevancia política del derecho del más fuerte”, en Sierra González, Convergencias y divergencias, 169. 
un modo plausible de existencia en estos tiempos de la cultura occidental.

El último capítulo, "Parménides y la globalización, o la política sin poetas”, corre a cargo de Ińaki Marieta, quien sostiene que es posible encontrar en Parménides, tan apreciado por Heidegger, un tipo de fundamento, incluso germinal, de la globalización. Insiste en que la globalización no sólo debe pensarse como tecnología y flujos de economía impulsados por la informática y las telecomunicaciones. Para él habría que pensar una "relación esencial de Parménides con la globalización, aun sabiendo que el de Elea nuca tuvo conexión a internet". ${ }^{10}$

Además del internet hay otras claves “originarias y esencializantes", es decir, la globalización sólo sería posible gracias a "esa red tejida con la lengua y el decir griegos en su especificidad crítica y metafísica" que hoy "llamamos filosofía". ${ }^{11} \mathrm{El}$ despliegue de la globalización "obedece a un destino (Geschick) enunciado original- mente por Parménides en su Poema, mediante uno de los nombres con los que dice (légei) el ser: eukyklós sfairé, 'esfera bien redonda". ${ }^{12}$

Como se nota, no sólo en el capítulo final, el libro está hecho de lecturas diversas y, como bien lo indica el título, heterodoxas. Ésta es una de las razones más importantes para su discusión: se trata de lecturas centradas en preocupaciones asumidas plenamente desde el pensar filosófico, sin duda habrá que aclarar que son preocupaciones primordialmente europeas. Bien podrían aportar a la discusión latinoamericana, sobre todo porque al tiempo que son escritas Ecuador, Chile y Haití explotan en protestas que exigen otro paradigma civilizatorio apartado de aquel donde la ley y la justicia del más fuerte imperan, como atinadamente escribe Ángela Sierra en su revisión del Gorgias de Platón. Probablemente al mirar al otro lado del Atlántico, incluso en casos como los de Hong Kong y España, es posible

\footnotetext{
10 Ińaki Marieta, "Parménides y la globalización, o la política sin poetas”, en Sierra González, Convergencias y divergencias, 184.

11 "Parménides y la globalización”, 185-186.

12 “Parménides y la globalización”, 188-189.
} 
iniciar una crisis (Krisis) del pensar que posibilite nuevos procesos cognitivos transformadores de nuestra realidad y pensamiento, que abra caminos para nuevas identidades al modo de Ariadna y su habitar en los pliegues. En ese sentido, es probable que todavía encontremos en los griegos mucho por descubrir, preguntas por renovar e inventar, para pensar la globalización y los cruces míticos que en nuestro momento histórico se entrelazan con la política y la religión, temas en los cuales, sin lugar a dudas, los griegos tienen mucho todavía por ofrecer.

Este libro, además, tiene el mérito de ser una obra colectiva, un trabajo que es construcción de pensamiento diverso por ser de muchos, unido por preocupaciones e intereses. Sería necesario más espacio para discutir esa voluntad de lo colectivo por sí mismo y darle una justa dimensión.

Ahora bien, no es posible terminar esta reseña crítica sin hacer notar algunos apuntes sobre las debilidades del libro, por ejemplo, que ciertos capítulos están mejor logrados que otros, eso es notorio, pues algunos son estructuralmente inciertos y otros son argumentativamente sólidos. Por otro lado, la edición no está a salvo de complicaciones, por ejemplo, no hay uniformidad en el estilo de citación, algunos utilizan el método parentético, otros la nota al pie e incluso la nota al final del capítulo; debido a esto, da la impresión de que algunas de las referencias no están completas.

Con todo, estamos ante una lectura de la filosofía griega que no pretende la recuperación romántica de un pasado perdido y, quizá por eso, las posibilidades abiertas son múltiples y permiten reflexionar desde una conciencia de mediación, desde la impureza, ya no desde la consolatoria nostalgia de una época pasada, sino de una apropiación vigorosa y vigente inserta en las problémicas de nuestro convulso mundo contemporáneo. 